\title{
Inclusão da criança deficiente visual na escola especial e regular: percepções da família
}

\author{
Inclusion of visually-impaired children in special and regular schools: the family's perceptions \\ Inclusión del niño portador de deficiencia visual en la escuela especial y regular: percepciones \\ de la familia
}

\author{
Aline Campelo Pintanel'; Giovana Calcagno Gomes" ${ }^{I I}$ D Daiani Modernel Xavierill; \\ Glaucia Dal Omo NicolarV; Tânia Cristina Schafer Vasques ${ }^{\text {V }}$ Mara Regina Santos da Silva ${ }^{\text {VI }}$
}

\begin{abstract}
RESUMO: Objetivou-se conhecer as percepções da família acerca da inclusão da criança deficiente visual na escola especial e regular. Realizou-se uma pesquisa qualitativa, no segundo semestre de 2011, com 10 mães de crianças atendidas em uma escola especial para deficientes visuais, no Sul do Brasil. Os dados foram coletados mediante entrevistas semiestruturadas e submetidos à análise temática. A família reconhece a escola especial como fonte de apoio, local adaptado, onde a criança é auxiliada a desenvolver suas habilidades e preparada para a entrada na escola regular. Percebe-se que a escola regular não está preparada para atender as necessidades especiais da criança e para a educação de cegos. Concluiu-se que a escola precisa incorporar a inclusão como filosofia e meta, sendo fundamental o preparo dos professores para a educação destas crianças. O enfermeiro pode ser um facilitador desse processo, sendo uma ponte entre a criança, a escola e a família.

Palavras-Chave: Educação de pessoas com deficiência visual; criança; família; enfermagem.
\end{abstract}

ABSTRACT: The objective was to discover families' perceptions of the inclusion of visually-impaired children in regular and special schools. This qualitative study was conducted in the second half of 2011 with ten mothers of children attending a special school for the visually impaired. Data were collected by semi-structured interview and subjected to thematic analysis. The families recognized the special school as a source of support, an adapted facility where the children are helped to develop their skills and prepared for entry into regular school. Regular schools are perceived as unprepared to meet the children's special needs and to educate the blind. It was concluded that schools need to incorporate inclusion as a philosophy and goal, and that teacher training is fundamental to these children's education. Nurses can be enablers in this process by bridging between child, school and family. Keywords: Education; visually impaired; child; family; nursing.

RESUMEN: Estudio cuyo objetivo fue conocer la percepción de la familia acerca de la inclusión de niños con discapacidad visual en escuelas regulares y especiales. Se realizó una investigación cualitativa en el segundo semestre de 2011, junto a 10 madres de niños atendidos en una escuela especial para discapacitados visuales, en el sur de Brasil. Los datos fueron recolectados por entrevistas semiestructuradas y sometidos al análisis temático. La familia reconoce la escuela de educación especial como fuente de apoyo, lugar adaptado, donde se ayuda al niño a desarrollar sus habilidades y a prepararse para el ingreso en la escuela regular. Queda claro que la escuela regular no está preparada para satisfacer las necesidades especiales de los niños y para la educación de los ciegos. Se concluye que la escuela necesita incorporar la inclusión como filosofía y reto, siendo fundamental la preparación de los profesores para la educación de estos niños. El enfermero puede ser un facilitador de este proceso, siendo un puente entre el niño, la escuela y la familia.

Palabras Clave: Educación de personas portadoras de discapacidad visual; niño; familia; enfermería.

\section{INTRODUÇÃO}

A deficiência visual (DV) é conceituada como a perda parcial ou total da capacidade de enxergar, seja por déficit em algum órgão ou no sistema visual ${ }^{1}$. A DV pode trazer inúmeras consequências limitantes para o desempenho de atividades na infância, como as dificuldades de locomoção, de compreensão e orientação espacial, limitações na comunicação e nas tarefas domésticas, bem como limitação para o autocuidado².

\footnotetext{
'Doutora em Enfermagem. Docente da Escola de Enfermagem e do Programa de Pós-Graduação da Universidade Federal do Rio Grande. Rio Grande do Sul, Brasil. E-mail: acpintanel@hotmail.com.

IIDoutora em Enfermagem. Docente da Escola de Enfermagem da Universidade Federal do Rio Grande. Rio Grande do Sul, Brasil. E-mail: giovanacalcagno@furg.com.br. IIIDoutoranda em Enfermagem. Universidade Federal do Rio Grande. Bolsista da Comissão de Aperfeiçoamento de Pessoal do Nível Superior e do Conselho Nacional de Desenvolvimento Científico e Tecnológico. Rio Grande do Sul, Brasil. E-mail: daiamoder@ibest.com.br.

IV Mestre em Enfermagem. Universidade Federal do Rio Grande. Rio Grande do Sul, Brasil. E-mail: glauianicola@hotmail.com.

v'Doutoranda em Enfermagem. Universidade Federal do Rio Grande. Rio Grande do Sul, Brasil. E-mail: taniacristina9@yahoo.com.br.

viDoutora em Enfermagem. Docente da Escola de Enfermagem e do Programa de Pós-Graduação da Universidade Federal do Rio Grande. Rio Grande do Sul, Brasil. E-mail: marare@brturbo.com.br.
} 
Observa-se que a orientação da criança portadora de DV dificilmente é desenvolvida quando esta não é abordada de maneira adequada e não trabalhada em espaços educativos ${ }^{3}$. Para a inclusão educacional da criança com DV, precisam-se propor métodos pedagógicos baseados na interação do aluno por meio de conteúdos pertinentes aos diferentes tipos de aprendizagem. Algumas aquisições levam mais tempo para serem compreendidas, com necessidade de permanente estimulação. A inclusão é um processo constante, gradual e interativo que requer a participação do próprio educando na construção de um ambiente escolar que lhe seja favorável ${ }^{4}$.

A educação regular é destinada às crianças sem limitações notórias e a educação especial, destinada àquelas que carecem de intervenção especial ${ }^{5}$. Compreende-se que a escola regular e a especial são capazes de interferir, positivamente, na construção da identidade da criança com DV. A partir do entrosamento entre grupos sociais diferentes daqueles de seu ambiente familiar, é possível que a criança adquira maiores possibilidades de adoção de um desenvolvimento saudável e independente, melhorando sua comunicação ou sociabilização ${ }^{6}$.

A inclusão da criança com DV na escola é garantida pela Lei Federal de no 9.394 , de 20 de dezembro de 1996, que estabelece as diretrizes e os direitos à educação dos portadores de deficiência ${ }^{7}$. Esta garante que as crianças com DV tenham respaldados os direitos à educação e à alfabetização ${ }^{6}$.

O Decreto $\mathrm{n}^{\circ} 3.298$, que regulamenta a Lei $\mathrm{n}^{\mathrm{o}} 7.853 / 89$, dispõe sobre a política nacional para a integração social dessas pessoas. No seu Artigo 25, estabelece que os serviços de educação especial serão ofertados em escolas especializadas, exclusivamente, quando a educação das escolas regulares não puder satisfazer as necessidades educativas ou sociais do aluno ${ }^{8}$. Este decreto reconhece a escola regular como sendo o melhor ambiente pedagógico para este tipo de aluno, reservando a educação especial apenas para aqueles considerados incapazes de integração na educação regular. No entanto, muitos obstáculos fazem com que a escola regular não se encontre, na prática, preparada para receber este tipo de aluno, tornando essa questão polêmica. A inserção da criança deficiente no ambiente escolar pode favorecer a experimentação de uma diversidade maior de atividades, promovendo seu desenvolvimento global, o aprimoramento de habilidades e capacidades, a superação de dificuldades e a descoberta de que ela é parte integrante e atuante da sociedade 9 .

As escolas especiais para deficientes visuais são estabelecimentos em que todos os alunos possuem DV. Em Rio Grande, município do sul do Brasil, tem-se a Escola de Educação Especial José Alvares de Azevedo, também conhecida como Escola de Cegos. Neste local, desenvolvem-se diversas atividades, destacando-se a alfabetização pelo método Braille, a estimulação motora e cognitiva, aulas de teatro e educação física, ensino do autocuidado e de atividades da vida diária bem como o acompanhamento da criança com DV por pedagogos, educadores físicos, psicólogos, fisioterapeutas, assistentes sociais e médicos. Poder contar com um local no qual a criança com DV possa conviver com profissionais capacitados para a educação especial apresenta-se como importante fonte de apoio e estímulo ${ }^{10}$.

Essas crianças, após serem alfabetizadas pelo método Braille, são incluídas em escolas regulares. O processo de inclusão da criança com DV, tanto na escola especial como na regular, é favorecido à medida que haja o envolvimento da família como apoiadora do aluno nesta nova trajetória ${ }^{11}$. A integração entre escola e família é fundamental no processo de inclusão, minimizando barreiras consideradas como obstáculos na obtenção da independência infantil neste ambiente ${ }^{12}$.

O enfermeiro pode atuar no processo de integração social da criança com DV, fazendo parte ativa na equipe de reabilitação, incrementando ações educativas que ajudem na aquisição de habilidades para o autocuidado e no desenvolvimento de uma consciência crítica que facilite a sua integração social. Deve orientar a família da criança com DV para que esta se torne o principal núcleo de estimulação infantil, favorecendo sua escolarização.

Para isso, é preciso conhecer suas percepções acerca da inclusão da criança cega na escola. Nesse contexto, teve-se como questão norteadora: Como a família percebe a inclusão da criança com DV tanto na escola especial como na regular? A partir desse questionamento, objetivou-se conhecer as percepções da família acerca da inclusão da criança deficiente visual na escola especial e regular.

\section{REVISÃO DE LITERATURA}

A família é essencial para o ingresso de crianças deficientes na escola. Ela é o contato direto da criança com a inclusão, já que vivencia as realidades e as mudanças necessárias para a valorização da independência da criança ${ }^{13}$.

Para que a criança com deficiência tenha um bom desempenho na escola, são necessárias transformações no sistema de ensino como a qualificação de professores ${ }^{14}$. Sem capacitação, os professores podem não satisfazer as necessidades das crianças com DV, não potencializando suas capacidades de independência ${ }^{13}$.

Percebe-se que várias conquistas foram feitas pelos portadores de DV. No entanto, o empenho para a melhoria da educação precisa continuar. Cabe aos profissionais o direcionamento da atenção para as capacidades e para o 
desenvolvimento de habilidades infantis, redirecionando a atenção antes focada apenas na deficiência ${ }^{14}$. As necessidades oriundas da limitação visual devem ser sanadas, entendendo as diferenças como desafios positivos, tendo as ações profissionais a finalidade de maximizar as potencialidades infantis frente à DV ${ }^{6}$.

\section{Metodologia}

Trata-se de uma pesquisa descritiva com abordagem qualitativa. A pesquisa descritiva investiga o fenômeno investigado, possibilitando sua compreensão por meio das experiências vividas ${ }^{15}$. É qualitativa porque trabalha com um universo de significados, motivos, aspirações, crenças, valores e atitudes ${ }^{16}$.

A pesquisa foi realizada no segundo semestre de 2011, em uma Escola de Educação Especial para Deficientes Visuais, localizada no sul do Brasil. Esta possui salas de aula, nas quais os alunos têm o ensino do primeiro ao quarto ano do ensino fundamental, além de salas de recursos, estimulação sensorial, informática, biblioteca, artesanato, cerâmica e educação física, com a prática de esportes como futsal e judô, dança e de ensino na realização de atividades de vida diária (AVDs), como arrumar a cama, cozinhar e outras.

Participaram 10 familiares de crianças com DV, que atenderam ao critério de inclusão: cuidar da criança cega continuamente no ambiente familiar e acompanhá-la nas suas atividades na escola especial e regular. Foram excluídos os cuidadores que não prestam cuidados contínuos à criança com DV. Das 10 crianças, oito frequentam a escola especial para deficientes visuais e duas frequentam tanto esta como a escola regular.

Os dados foram obtidos mediante entrevista semiestruturada, agendadas previamente. Esta constituiu-se de um roteiro com questões relativas à sua percepção acerca da inclusão da criança portadora de DV na escola especial e na escola regular. Os dados foram analisados pela técnica de análise temática ${ }^{15}$, operacionalizada em três etapas: pré-análise, na qual foram identificadas as unidades de registro que orientaram a análise; exploração do material, em que os dados iniciais obtidos foram classificados e agregados em categorias; e tratamento dos resultados obtidos, na qual se realizou a interpretação dos dados, correlacionando-os com autores estudiosos da temática.

Todos os preceitos da Resolução no 196/96 do Conselho Nacional de Saúde para a pesquisa com seres humanos foram levados em consideração ${ }^{17}$. O projeto foi encaminhado a um Comitê de Ética e Pesquisa, sendo aprovado sob n ${ }^{\circ} 105 / 2011$. As falas dos familiares foram identificadas pela letra F, seguida do número da entrevista, com vistas a garantir o seu anonimato.

\section{Resultados}

A análise temática dos dados gerou duas categorias, que são analisadas a seguir.

\section{Percepções da família: inclusão da criança na escola especial}

Uma das fontes de apoio essencial no auxílio à família para o cuidado à criança com DV é a existência da Escola Especial para Deficientes Visuais. Poder contar com um local no qual a criança com DV convive com profissionais capacitados para a educação especial e com outras crianças com DV apresenta-se como importante suporte e estímulo para o desenvolvimento das potencialidades das crianças.

Uma das facilidades foi vir aqui na escola, porque é um lugar voltado para isso, para ensinar a conviver. Aqui ela convive com outras crianças cegas e com profissionais preparados para ensinar crianças cegas. (F1)

Ela teve uma professora, aqui, na escola, que ensinava para ela como andar sem se bater nas coisas, como arrumar a roupa. [...] começou a testar ela, até ver que ela é esperta e isso facilita tudo. Os professores ajudam ela a se desenvolver. (F4)

A inclusão da criança com DV na escola especial auxilia o familiar cuidador a se engajar no cuidado de seu filho. Faz com que se coloque à disposição para ajudar e aprender como lidar com as tarefas diárias e a convivência junto a essas crianças.

Aqui ela convive com outras crianças cegas e convive com profissionais preparados para ensinar. [...] Estando aqui como voluntária eu aprendo muito a cuidar do meu filho no dia a dia. (F1)

Aqui, na escola, tive o apoio que eu precisava para cuidar dela. Ver minha filha bem tratada pelos professores me ajuda. Aqui, no centro, todo mundo se empenha, porque é um lugar voltado para isso. Preparado para ensinar a conviver. (F2)

A participação da criança nas atividades da escola especial possibilita a convivência do familiar com profissionais habilitados a ensinar às crianças. Assim, a aquisição de conhecimentos relativos à DV apresenta-se como um facilitador para o cuidado familiar à criança.

A professora me ajudou a aprender a cuidar dele [...] eu corri atrás, mas com apoio da escola eu aprendi muito. (F10)

Aqui, na escola, eu fui direcionada a aprender. Não é bom só para as crianças. A gente aprende a estimular a criança. (F3)

Referiram que, na escola especial, a criança interage com outras crianças com DV. Essas brincam de forma calma e devagar e que a criança com DV se sente feliz por ser entendida, podendo desenvolver 
suas habilidades aos poucos, sentindo-se segura e confiante.

Aqui, na escola de cegos, as crianças a ajudam e a levam para dentro da escola e brincam. Ela se sente feliz em brincar com quem a entende, no ritmo dela. Aqui ela vai aprendendo aos poucos, sem pressa e se sente confiante. (F4)

Aqui, as brincadeiras com as crianças são mais devagar, mais calmas. No tempo dele. Ele se sente seguro. (F5)

A família percebe que a escola especial está adaptada para a educação de cegos, possibilitando que as crianças com DV tenham suas necessidades especiais de cuidado e de educação atendidas.

A escola é preparada para a educação de cegos. É uma instituição para deficientes visuais, tem corrimãos para facilitar o deslocamento, todos os trabalhos são em alto relevo, ensinam a ler pelo método Braille, tem sala de informática adaptada. Então, é uma escola própria, preparada para cegos. (F10)

A escola especial é reconhecida pela família como preparatória da criança com DV para a entrada na escola regular. Além disso, oferece reforço de conteúdos para que ela consiga acompanhar, depois, as crianças videntes, sendo um apoio para a família.

Conseguir uma vaga para minha filha estudar, aqui, foi importante porque é um preparatório para a escola regular. Ela já saiu daqui sabendo ler e escrever em Braille e a se relacionar com as outras crianças. Aqui ela faz reforço das matérias que aprende lá. Esta complementação vai possibilitar que consiga acompanhar as outras crianças. (F4)

\section{Percepções da família: acerca da inclusão da criança na escola regular}

A família percebe o ensino regular como importante para o desenvolvimento de seus filhos.

$\mathrm{O}$ ano que vem ele sai daqui. Ele já está alfabetizado. Vai para a escola comum. Lá as crianças especiais se dão bem. Eu acho que ele está bem preparado e não vai ter problema. É importante esta inclusão no mundo dos videntes. (F3)

Frequentar a escola regular faz com que a criança passe a conviver com crianças videntes, sendo desafiada a acompanhá-las, desenvolvendo novas habilidades e competências.

Nos primeiros dias, ele demorou a se soltar e ir brincar. [,,,]. Aí, quando as crianças perceberam que ele brincava normal começaram a chamá-lo. Só que isso demorou uns dias. Agora ele está acostumado, brinca no ritmo delas, tem que fazer os exercícios rápido. [...] É um desafio novo a cada dia. (F3)

Ela vai à escola normal e até gosta mais do que a escola de cegos. Porque lá as crianças são mais agitadas. Ela me diz que gosta de correr, andar de balanço. Que não quer ficar parada só ouvindo os outros brincarem. (F4)
A família teme que na escola regular as necessidades da criança não sejam levadas em conta, pois não se trata de uma escola especializada. Acreditam que esta transição exigirá da criança com DV uma adaptação, mas será importante para a aquisição de independência.

É um medo de todas as mães daqui porque aqui, na escola, tudo é adaptado. Mas um dia ela tem que sair daqui [...]. Aí começa outro problema. Será que na outra escola vai ser igual? (F7)

Não sei como ela vai se adaptar, mas acho que a escola normal é um teste de independência. (F2)

A família teme que os profissionais atuantes na escola regular desconheçam como atuar junto à criança com DV, não estando prontos para recebê-la. A família refere que os professores da escola regular não receberam um preparo prévio para educar uma criança com DV.

Quando ele imprimir os trabalhos em Braille ele vai dar para a professora corrigir. Mas ela vai saber corrigir o Braille? Sem ter tido um preparo prévio? (F9)

Algumas famílias desacreditam na possibilidade do filho frequentar com sucesso esta escola, vendo a inclusão como algo difícil e que trará sofrimento para a criança, devido ao preconceito que possa sofrer por ser cega. Algumas relataram a vivência pela criança de situações de bulling.

Tem preconceito dos colegas. Eles riem dela. Agora tem um nome para isso [bulling]. Se sem estas situações já não é fácil, imagina isso todo dia. Ela diz que não quer ir mais. (F6)

Na escola normal, ela é chamada de quatro olhos, de criança cega. Aí ela chora! [...] Falei com as professoras, mas nunca fazem nada. Não sabem como lidar com a situação. (F8)

Apesar de acreditarem que seja benéfico o convívio da criança com DV com crianças videntes, aparentemente, percebem que elas não têm paciência com o ritmo lento da criança com DV.

Falta paciência das outras crianças que enxergam porque elas têm que brincar no tempo dele e isso nem sempre elas aceitam. Tem que esperar ele entender a brincadeira e se preparar. (F5)

Os familiares sentem-se limitados na escolha da escola regular, na qual irá colocar seus filhos, pois acreditam que muitas escolas resistem em receber crianças com DV.

A única escola que eu sei que tem recursos para o Braille é o [...]. Mas isso acaba limitando. E se eu não quiser colocar ele lá? E se eu quiser uma escola particular. Eu sei que as escolas têm uma resistência em receber. (F3) 


\section{Discussão}

Apesar de a criança com DV ter direito à educação e à alfabetização, com respaldo legal, ela depende da família para exercê-lo. Frente à DV, indica-se o encaminhamento da criança para os centros de reabilitação e ensino para deficientes visuais e para a escola regular $^{2}$. Estes apresentam-se como apoios à família no desenvolvimento dessa criança.

Os pais de crianças com DV podem apresentar dúvidas e dificuldades na estimulação educacional delas, necessitando de orientações de forma efetiva. A escola especial mostra-se um local onde a criança interage com outras crianças com DV, professores e familiares, no qual a família encontra apoio e orientação ${ }^{11}$.

É um local adaptado, no qual a criança com DV convive com profissionais habilitados para auxiliá-la a desenvolver suas habilidades ${ }^{10}$. A educação especial ganha destaque e é reconhecida como uma modalidade de ensino importante como suporte da rede regular de ensino ${ }^{18}$.

Nessa modalidade de ensino, geralmente, é utilizado um processo dialógico, facilitado por recursos personalizados, conteúdos atualizados e informações específicas, com caráter lúdico e comunicacional. Para isso, a criança e a família convivem com profissionais específicos que entendem sobre as melhores formas de comunicação com essas crianças ${ }^{19}$. O educador, na escola especial, tem como tarefa auxiliar no processo de aprendizagem da criança com DV, considerando seu ritmo próprio. A utilização de estratégias pedagógicas diferenciadas pode ser pensada como um recurso, que possibilita o acesso dos alunos ao conhecimento e é descrita como elemento facilitador para efetivar com qualidade o processo de inclusão escolar de crianças com deficiência na escola regular ${ }^{20}$.

Quanto à escola regular, a proposta de inclusão educacional de alunos com deficiência nesse sistema de ensino assegura respostas às necessidades específicas e educacionais especiais no cotidiano escolar. Para tanto, torna-se fundamental que essas necessidades sejam adequadamente identificadas e atendidas ${ }^{21}$.

Acredita-se que a convivência de crianças cegas com crianças normovisuais pode contribuir para sua adaptação na escola, levando-a a sentir-se semelhante em capacidade e potencialidades. Durante a interação com essas crianças, ela pode construir sua ideia de relações, é desafiada e testada quanto a suas capacidades de adaptação e tolerância.

Estudo constatou a importância do faz de conta no desenvolvimento infantil frente à limitação visual. Os autores observaram que as crianças cegas desenvolviam ações diferentes daquela desenvolvidas no cotidiano. Várias competências, antes não reveladas, surgiram durante as interações com outras crianças, possibilitando que se tornem mais seguras ${ }^{22,23}$.

A família, ao colocar a criança com DV em uma escola regular, teme que a escola e os professores não estejam preparados para a sua educação. Em estudo acerca do olhar das mães para a inclusão escolar de crianças e adolescentes, com necessidades educacionais especiais, observou-se que apenas $17 \%$ delas identificaram a escola regular como um local acolhedor e adequado às necessidades especiais das crianças, $60 \%$ relataram que as escolas não apresentavam preparo em função da falta de profissionais capacitados, de estrutura adequada e recursos que facilitassem o aprendizado das crianças ${ }^{13}$.

Ao incluir a criança na escola, a família teme que esta sofra, devido às dificuldades que terá que enfrentar por causa da DV. Mães de crianças com DV relataram que os filhos são vítimas de preconceito e exclusão na escola regular, podendo comprometer sua aprendizagem ${ }^{13}$. Ao perceber que estão sendo discriminados, os alunos podem apresentar sentimento de rejeição e humilhação, que dificultam o desenvolvimento psicossocial ${ }^{24}$. Assim, há a necessidade da escola tornar-se um contexto de superação de estigmas, preconceitos e barreiras atitudinais e pedagógicas, a favor da inclusão ${ }^{19}$.

Outra dificuldade apontada foi a impaciência de professores e alunos com o ritmo mais lento da criança com DV. Estudo revelou que o desenvolvimento da criança com DV segue a mesma sequência da criança vidente, apenas com a alteração do ritmo, levando a uma aprendizagem mais lenta. Tal condição requer paciência e atenção especial, em todos os níveis de aprendizagem ${ }^{24}$.

A família percebe que os professores da escola regular não possuem preparo para ensinar crianças com deficiência. Pesquisa sobre a inclusão escolar de alunos com DV mostrou que o que mais dificulta a inclusão é a falta de disponibilidade dos professores para detectarem as necessidades do escolar e adaptarem-se a elas, procurando recursos e outras estratégias para ensiná-los. Os professores relataram dificuldade em ensinar ao aluno com DV, não conseguindo transmitir o conhecimento necessário como aos demais alunos. Tal postura pode causar ao escolar sentimentos de frustração e incapacidade ${ }^{6}$.

Percebe-se que várias conquistas foram feitas pelos portadores de DV. No entanto, os empenhos para a melhoria da educação precisam continuar. Cabe aos profissionais o direcionamento da atenção para as capacidades e para o desenvolvimento de habilidades infantis, redirecionando a atenção antes focada apenas na deficiência ${ }^{14}$. 


\section{CONCLUSÃO}

Os dados do estudo apontam que a família precisa ser preparada para auxiliar a criança com DV no seu processo de escolarização, sendo orientada sobre formas corretas de driblar as limitações causadas pela DV. Os profissionais da enfermagem precisam olhar com atenção para a família da criança com DV, buscando garantir-lhe informações, habilitando-a para o cuidado à criança na perspectiva da sua independência. É preciso auxiliá-la na escolha de estratégias efetivas de cuidado capazes de desenvolver seu potencial, sendo estimuladas em casa ou na escola.

Cabe ao enfermeiro o papel de facilitador no processo de escolarização da criança com DV, realizando consultorias, debates, oficinas, grupos de estudo com os professores acerca das questões que envolvem a saúde e a condição limitante dessa criança. Deve realizar, também, assistência individual ao portador de DV, possibilitando a exposição de suas dificuldades, enfrentadas durante sua inclusão na escola, como uma ponte entre a criança com DV, a escola e a família na busca por soluções.

Apesar da legislação existente, conclui-se como importante o auxílio da escola especial no sentido de preparar a criança com DV para ser inserida, na escola regular, mais instrumentalizada, sendo fonte de apoio e reforço à criança com DV e à família. Novos estudos devem ser realizados no sentido de apontar estratégias efetivas para a facilitação da inclusão dessas crianças na escola.

\section{REFERÊNCIAS}

1.Costa LEL, Quirino MD, Lopes RLM, Suto CSS. A imagem da cegueira no cinema: análise da deficiência visual pelos portadores. Revenferm UFPE online. 2011; 5:1468-74.

2.Degrazia JEC, Pellin JOF, Degrazia DF. Detecção e prevenção das deficiências visuais na infância. Rev AMRIGS. 2010; 54:466-70.

3.Chien CW, Brown T, Mcdonald R. A framework of children's handskills for assessmentand intervention. ChildCare Health Dev. 2009; 35:873-84.

4.Motta JA, Silva PO, Marta CB, Araújo BBM, Francisco MTR, Seabra Junior HC.O cuidado à criança na creche: integração entre saúde e educação. Rev enferm UERJ. 2012; 20:771-6.

5.Figueiredo FJC. Duas crianças cegas congênitas no primeiro ciclo da escola regular. CadPesqui.2010; 40(139):95-119.

6.Florence MYL, Tsang JFK, Mandy MY Chui Lee MYF, Janice FK Tsang, Chui MMY. The needs of parents of children with visual impairment studying in mainstream schools in Hong Kong. Hong Kong Med J. 2014; 20:413-20. 7.Câmara dos Deputados. Legislação brasileira sobre pessoas portadoras de deficiência. $5^{a}$ ed.Brasília (DF):
Edições Câmara; 2009.

8.Ministério da Saúde (Br). Coordenação Nacional para Integração da Pessoa Portadora de Deficiência. Brasília (DF): Ministério da Saúde; 2014.

9.Vitta FCF. A inclusão da criança com necessidades especiais na visão de berçaristas. CadPesqui. 2010; 40(139):75-93.

10.Pintanel AC, Gomes GC, Xavier DM. Mães de crianças com deficiência visual: dificuldades e facilidades enfrentadas no cuidado.Rev Gaúcha Enferm. 2013; 34(2):86-92.

11.Toussaint KA, Tiger JH. Teachingearlybrailleliteracy skills within a stimulus equivalence paradigm to children with degenerative visual impairments. J Appl Behav Anal. 2010; 43:181-94.

12. Oliveira SC, Negrão MV. Ações de inclusão: valorização da acessibilidade em uma escola profissionalizante. E-Tech. 2010; 3(1):48-62.

13.Resende DO, Ferreira PM, Rosa SM. A inclusão escolar de crianças e adolescentes com necessidades educacionais especiais: um olhar mães. Cad Ter Ocup UFSCar. 2010; 18:115-27.

14.Pereira JLC, Costa MPR. O aluno com deficiência visual em sala de aula: informações gerais para professores de artes. Reveduc. 2009; 3(1): 89-99.

15.Triviños ANS. Introdução à pesquisa em ciências sociais: a pesquisa qualitativa em educação. São Paulo: Atlas; 2009.

16.Minayo MCS. Pesquisa social: teoria, método e criatividade. $29^{\mathrm{a}}$ ed. Petrópolis (RJ): Vozes; 2010.

17.Ministério da Saúde (Br). Conselho Nacional de Saúde. Resolução n ${ }^{\circ}$ 196, de 10 de outubro de 1996: diretrizes e normas regulamentadoras de pesquisas envolvendo seres humanos. Brasília (DF): CNS; 1996. 18.Lyncha P, McCalla S, Douglasa G, McLindena M, Mogesab B, Mwaurac M, et al.Inclusive education alpractices in Kenya: evidencing practice of itinerante achers who work with children with visual impairment in local mainstream schools. Int J EducDev.2011; 31:478-88.

19.Maslov KS. Making things visible: the dialogical and themonological within the human nature. Cult Psychology. 2013; 19:203-12.

20.Whitburn B.'A really good teaching strategy': secondary students with vision impairment voice their experiences of inclusive teacher pedagogy. BJVI. 2014; 32:148-56.

21.Boera A, Pijlb SJ, Minnaerta A. Regular primary school teachers' attitudes towards inclusive education: a review of the literature. IJIE. 2011; 15:331-53.

22.Hueara L, Souza CML, Batista CG, Melgaço MB, Tavares FS. O faz-de-conta em crianças com deficiência visual: identificando habilidades. Rev bras educ espec. 2006; 12:351-68.

23.Ferroni GM, Gil MSCA. A importância da mediação do adulto na brincadeira de uma criança cega.RIEED. 2012; 7(3):62-72.

24.Franca-Freitas, Pontes ML, Gil MSCA. O desenvolvimento de crianças cegas e de crianças videntes. Rev bras educ espec. 2012; 18:507-26. 